\title{
On New Algebraic Systems
}

\author{
Mehsin Jabel Atteya* Dalal Ibraheem Ressan*
}

Date of acceptance 24/10/2007

\begin{abstract}
: systems groupoid, group and ring. Group.

\section{Introduction:}

Many authors work for development and findout some mathematics systems .Al- Lahham [1] one of them, he was introduced new algebraic system flower, garden and farm ,he gave some results about them as a finite farm $(\mathrm{S}, *, \diamond)$ such that $|S|>2$, is not a field .Al-Lahham introduced type of groups is called a Lahhamian group, during his work depended on [2] and [3]. We can say he find some relations between his systems with another accustomed algebraic systems.
\end{abstract}

The purpose of this paper is to give some results theorems, propositions and corollaries concerning new algebraic systems flower, garden and farm with accustomed algebraic

Keywords: Groupoid , Group , Ring ,Semiflower , Flower , Garden ,Farm , Lahhamian

\section{Preliminaries :}

Throughout this paper $\mathrm{S}$ denote to a groupoid is an order pair $(\mathrm{S}, *)$ where $\mathrm{S}$ is a non empty set and $*$ is a binary operation on $S$ [2] unless explicily stated .A binary operation $*$ on non empty set $\mathrm{S}$ is ATL if for all $a, b, c \in S, a *(b * c)=c *$ $(b * a)$.Asemiflower is an order pair $(\mathrm{S}, *)$ where $\mathrm{S}$ is a non empty set and $*$ is an ATL binary operation on $S$.Aflower is an order pair $(\mathrm{S}, *)$ where $\mathrm{S}$ is a non empty set and $*$ is a binary operation on $\mathrm{S}$ satisfying the following axioms :

( i ) a $*(b * c)=c *(b * a)$ for all a,b,c $\in \mathrm{S}$ (ATL law).

( ii )There exists an element e in $\mathrm{S}$ such that $\mathrm{a} * \mathrm{e}=\mathrm{a}$ for all $\mathrm{a} \in \mathrm{S}(\mathrm{e}$ is a right identity of $S$ ). (iii ) a $* \mathrm{a}=\mathrm{e}$ for all $\mathrm{a} \in \mathrm{S}$.Agroup $(\mathrm{S}, *)$ is called Lahhamian group if $\mathrm{a} * \mathrm{a}=\mathrm{e}$ for all $a \in S$, where e the identity of $S$.

Agarden is a triple $(\mathrm{S}, *, \diamond)$, where $\mathrm{S}$ is non empty set has at least two elements , $*$ and $\diamond$ are two binary operations on $\mathrm{S}$, $\left(\diamond: S \times S^{*} \rightarrow S\right)$ and $S^{*}=S-\{0\},(0$ is the right identity in $\quad(\mathrm{S}, *))$, satisfies the following axioms:

( i ) $(\mathrm{S}, *)$ is a flower .( ii) $\diamond$ is ATL (i.e.a $\diamond(b \diamond c)=c \diamond(b \diamond a)$ for all $\left.a, b, c \in S^{*}\right)$.

( iii )The distributive law, $(\mathrm{a} * \mathrm{~b}) \nabla \mathrm{c}=$ $(\mathrm{a} \diamond \mathrm{c}) *(\mathrm{~b} \diamond \mathrm{c})$ for all $\mathrm{a}, \mathrm{b} \in \mathrm{S}, \mathrm{c} \in \mathrm{S}^{*}$, holds in $\mathrm{S}$. A farm $(\mathrm{S}, *, \diamond)$ is a garden such that $\left(S^{*}, \diamond\right)$ is aflower.A function $\mathrm{p}[\lambda]$ from a flower $S$ to $S$ is a right (left)translation of $\mathrm{S}$ if $\mathrm{p}(\mathrm{a}) \mathrm{b}=\mathrm{a}(\mathrm{P}(\mathrm{b}))$ $[\lambda(\mathrm{ab})=\lambda(\mathrm{a}) \mathrm{b}]$ for all $a, b \in S$.The operation o is composition of functions.

Now, we will mention some results which we need to a chieve our work which apperared in[1]

\section{Lemma 1 [Lemma 4]}

Let $(S, *, \diamond)$ be a garden, then for all a $\in \mathrm{S}^{*}, 0 \diamond \mathrm{a}=0$.

\section{Lemma 2[Theorem6]}

A flower $(\mathrm{S}, *)$ is a Lahhamian group if and only if it is commutative .

\section{Lemma 3[Theorem4]}

*Al- Mustansiriyah University-College of Education - Department of Mathematics 
Let $S$ be a flower, then every right translation of $S$ commutes with every left translation of $S$.

\section{Proposition 5[Proposition 2]}

If $(\mathrm{S},$.$) is an abelian group ,then \mathrm{S}$ with the new binary operation $*$ defined as follows $: a * b=a \cdot b^{-1}$ for all $a, b \in S$ is a flower .

\section{Lemma 4[Lemma2]}

If $(\mathrm{S}, *)$ is a flower then for all $a, b \in S, a * b=e *(b * a)$.

\section{Proposition 6[ Proposition1]}

If $(\mathrm{S}, *)$ is a flower then, $(\mathrm{b} * \mathrm{c})$ $* a=(b * a) * c$ for all a,b,c $\in \mathrm{S}$.

\section{Proposition 7[ Proposition3]}

If $S$ is a Lahhamian group then $S$ is a flower.

\section{Proposition 8[Theorem 8]}

Let $\left(\mathrm{S},{ }^{*}\right)$ be a flower ,then the following conditions are equivalent:

(i) $\mathrm{S}$ is a Lahhamian group.

(ii) $\mathrm{S}$ has an identity.

(iii) $\mathrm{S}$ is commutative.

(iiii) $\mathrm{S}$ is associative.

It is our aim in this paper to give some new results concerning new algebraic systems.

\section{The Main Results:}

\section{Theorem 1}

Let $(\mathrm{S}, *)$ be a non-empty set such that a is idempotent element of $\mathrm{S}$, * satisfy ATL law and left cancellation law hold in S,then $(\mathrm{S}, *)$ is flower .

Proof $:$ We have $a * a=a, a \in S$, $*$ satisfy ATL law .Then we must be prove

(i) ${ }^{*}$ e $=a, a \in S$. By replacing e by a, we obtain

$\mathrm{a} * \mathrm{e}=\mathrm{a} * \mathrm{a}, \mathrm{a} \in \mathrm{S}$.Then

$=\mathrm{a}, \mathrm{a} \in \mathrm{S}$. Thus $\mathrm{e}$ is a right identity element of $\mathrm{S}$.

(ii) $\mathrm{a} * \mathrm{a}=\mathrm{e}, \mathrm{a} \in \mathrm{S}$. According to our relation, we have

$\mathrm{a}^{*} \mathrm{a}=\mathrm{a}, \mathrm{a} \in \mathrm{S}$. Since $\mathrm{e}$ is a right identity, then $\mathrm{a} * \mathrm{a}=\mathrm{a} * \mathrm{e}, \mathrm{a} \in \mathrm{S}$. Then $\mathrm{a}$ can be cancelled on the left our equation, we obtain $\mathrm{a}=\mathrm{e}$. Then $\mathrm{a} * \mathrm{a}=\mathrm{e}$

Thus $(\mathrm{S}, *)$ is flower.

\section{Remark 2}

In Theorem $1,(\mathrm{~S}, *)$ is a semiflower .

\section{Proposition 3}

If $(\mathrm{S}, *)$ is a flower then the following are true for all $a, b, c \in S$.

(1) $\mathrm{S}$ is closed under * (2) (e*a) * $(\mathrm{a} * \mathrm{e})=\mathrm{e}(\mathrm{e}$ is a right identity element of S). $\quad(3)(b * a) * a=b$

Proof: (1)Since * is binary operation, then for all $a, b \in S$, we obtain, $a * b \in S$, replacing $b$ by $a$, we have $a * a \in S$,by axaiom (iii ), we get $e \in S$, e is a right identity element of $\mathrm{S}$.

(2)We have $(\mathrm{e} * \mathrm{a}) *(\mathrm{a} * \mathrm{e})=\mathrm{e}$.Let $\mathrm{x}=(\mathrm{e} * \mathrm{a})$ and $\mathrm{y}=(\mathrm{a} * \mathrm{e})$, then

$\mathrm{x} * \mathrm{y}=\mathrm{e}$.We set $\mathrm{x}=\mathrm{e} * \mathrm{x}$ and $\mathrm{y}=\mathrm{y} * \mathrm{e}$ ,then

$(\mathrm{e} * \mathrm{x}) *(\mathrm{y} * \mathrm{e})$

$=(\mathrm{e} *(\mathrm{e} * \mathrm{a})) *((\mathrm{a} * \mathrm{e}) * \mathrm{e})$. By ATL

law ,we get

$=(\mathrm{a} *(\mathrm{e} * \mathrm{e})) *((\mathrm{a} * \mathrm{e}) * \mathrm{e})$

$=\mathrm{a} *((\mathrm{a} * \mathrm{e}) * \mathrm{e})$. Since $\mathrm{e}$ is a right identity element of $\mathrm{S}$

$=\mathrm{a} *(\mathrm{a} * \mathrm{e})$.By ATL law,we get

$=e^{*}(a * a)$. By axiom ( iii ),we obtain.

$=\mathrm{e} * \mathrm{e}=\mathrm{e}$.

(3) We have $(b * a) * a=b$,then

Replacing a by $\mathrm{e}^{*} \mathrm{a}$, we obtain

$(b * a) * a=(b *(e * a)) *(e * a)$. By

ATL law,we get

$=\left(\mathrm{a} *\left(\mathrm{e}^{*} \mathrm{~b}\right)\right) *\left(\mathrm{e}^{*} \mathrm{a}\right)$.By Proposition 6 ,we obtain

$=(\mathrm{a} *(\mathrm{e} * \mathrm{a})) *(\mathrm{e} * \mathrm{~b})$.By ATL law, we get

$=\mathrm{b} *(\mathrm{e} *(\mathrm{a} *(\mathrm{e} * \mathrm{a}))$.By ATL law, we obtain

$=\mathrm{b} *((\mathrm{e} * \mathrm{a}) *(\mathrm{a} * \mathrm{e}))$. By Part 2,then

$=\mathrm{b} * \mathrm{e}=\mathrm{b}$.

\section{Theorem 4}

Let $(\mathrm{S}, *)$ be a flower, if $\mathrm{a} * \mathrm{x}=\mathrm{y} * \mathrm{~b}$ then $\mathrm{x}=\mathrm{y}$ for all $\mathrm{a}, \mathrm{b}, \mathrm{x}, \mathrm{y} \in \mathrm{S}$.

Proof: We have $\mathrm{a} * \mathrm{x}=\mathrm{y} * \mathrm{~b}$ for all $a, b, x, y \in S$.Then 
$\mathrm{a} *(\mathrm{a} * \mathrm{x})=\mathrm{a} *(\mathrm{y} * \mathrm{~b})$ for all $\mathrm{a}, \mathrm{b}, \mathrm{x}, \mathrm{y} \in \mathrm{S}$. By ATL law,we obtain

$\mathrm{x} * \quad(\mathrm{a} * \mathrm{a})=\mathrm{b} * \quad(\mathrm{y} * \mathrm{a})$ for all $a, b, x, y \in$ S.By axiom (iii), we get $\mathrm{x} * \mathrm{e}=\mathrm{b} * \quad(\mathrm{y} * \mathrm{a})$ for all $\mathrm{a}, \mathrm{b}, \mathrm{x}, \mathrm{y} \in \mathrm{S}$. By axiom (ii), we obtain $\mathrm{x}=\mathrm{b} *(\mathrm{y} * \mathrm{a})$ for all $\mathrm{a}, \mathrm{b}, \mathrm{x}, \mathrm{y} \in \mathrm{S}$. Then $\mathrm{x} *(\mathrm{e} * \mathrm{e})=(\mathrm{b} *(\mathrm{y} * \mathrm{a})) *(\mathrm{e} * \mathrm{e})$ for all $a, b, x, y \in S$. By ATL law,we get $\mathrm{e}^{*}(\mathrm{e} * \mathrm{x})=\mathrm{e} *(\mathrm{e} *(\mathrm{~b} *(\mathrm{y} * \mathrm{a})))$ for all $a, b, x, y \in S$.By ATL law,we obtain $x *$ $(e * e)=e^{*}((y * a) *(b * e))$ for all $a, b, x, y \in$ S.By ATL law,we get $\mathrm{x} * \mathrm{e}=(\mathrm{b} * \mathrm{e}) *((\mathrm{y} * \mathrm{a}) * \mathrm{e})$ for all $a, b, x, y \in S$. Also by axiom( ii ), we obtain $\mathrm{x}=\mathrm{b} *(\mathrm{y} * a)$ for all $a, b, x, y \in S$. Since e is a right identity element of $S$,then $\mathrm{x}=\mathrm{b} *(\mathrm{y} *(\mathrm{a} * \mathrm{e}))$ for all $\mathrm{a}, \mathrm{b}, \mathrm{x}, \mathrm{y} \in \mathrm{S}$.By ATL law,we obtain $\mathrm{x}=\mathrm{b} *(\mathrm{e} *(\mathrm{a} * \mathrm{y}))$ for all $\mathrm{a}, \mathrm{b}, \mathrm{x}, \mathrm{y} \in \mathrm{S}$. By ATL law,we obtain $\mathrm{x}=(\mathrm{a} * \mathrm{y}) *(\mathrm{e} * \mathrm{~b})$ for all $\mathrm{a}, \mathrm{b}, \mathrm{x}, \mathrm{y} \in \mathrm{S}$.Let $\mathrm{b}=\mathrm{e} * \mathrm{~b}$, then

$\mathrm{x}=(\mathrm{a} * \mathrm{y}) \quad * \quad\left(\mathrm{e}^{*} \quad\left(\mathrm{e}^{*} \mathrm{~b}\right)\right)$ for all $a, b, x, y \in$ S.By ATL law ,we obtain $\mathrm{x}=(\mathrm{a} * \mathrm{y}) *(\mathrm{~b} * \mathrm{e})$ for all $\mathrm{a}, \mathrm{b}, \mathrm{x}, \mathrm{y} \in \mathrm{S}$. Then $\mathrm{x}=(\mathrm{a} * \mathrm{y}) * \mathrm{~b}$ for all $\mathrm{a}, \mathrm{b}, \mathrm{x}, \mathrm{y} \in \mathrm{S}$.By Proposition 6 , we obtain $\mathrm{x}=(\mathrm{a} * \mathrm{~b}) * \mathrm{y}$ for all $\mathrm{a}, \mathrm{b}, \mathrm{x}, \mathrm{y} \in \mathrm{S}$. Replacing $a$ by $b$,we obtain $\mathrm{x}=(\mathrm{b} * \mathrm{~b}) * \mathrm{y}$ for all $\mathrm{b}, \mathrm{x}, \mathrm{y} \in \mathrm{S}$.By axiom ( iii ), we obtain $\mathrm{x}=\mathrm{e} * \mathrm{y}$ for all $\mathrm{x}, \mathrm{y} \in \mathrm{S}$. Replacing y by e*y, we get

$\mathrm{x}=\mathrm{e}^{*}\left(\mathrm{e}^{*} \mathrm{y}\right)$ for all $\mathrm{x}, \mathrm{y} \in \mathrm{S}$.By ATL law ,we get $\mathrm{x}=\mathrm{y}$ for all $\mathrm{x}, \mathrm{y} \in \mathrm{S}$.

\section{Theorem 5}

If $(S,$.$) is an abelian group ,then S$ with the new binary operation * defined as follows: $a^{*} b=a^{-1} . b$ for all $a, b \in S$ is $a$ flower, where e is identity element for $*$ on S.

Proof: (i) $\quad c^{*}\left(b^{*} a\right)=c^{-1} .\left(b^{*} a\right)$ for all $a, b, c \in S$.

Since $S$ is belain then $c^{-1} \cdot\left(b^{-1} \cdot a\right)=a \cdot\left(b^{-1} \cdot c^{-1}\right)$ for all $a, b, c \in S$. Since e is identity element of $S$,we obtain
$=($ a.e $) \cdot(\text { b.c })^{-1}$

$=\left((\mathrm{b} \cdot \mathrm{c}) \cdot(\mathrm{a} \cdot \mathrm{e})^{-1}\right)^{-1}$ for all $\mathrm{a}, \mathrm{b}, \mathrm{c} \in \mathrm{S}$.

$=\left((b \cdot c) \cdot\left(a^{-1} \cdot e^{-1}\right)\right)^{-1}$ for all $a, b, c \in S$.

$=\left(a^{-1} \cdot e^{-1}\right)^{-1} \cdot(b \cdot c)^{-1}$ for all $a, b, c \in S$. Since e

is identity element of $S$, we get $=\left(\left(a^{-1} \cdot e\right) \cdot e^{-}\right.$

$\left.{ }^{1}\right)^{-1} \cdot\left(b^{-1}\right.$.e. $c^{-1}$.e $)$ for all a,b,c $\in$ S. Then

$=\left(\left(a^{-1} \cdot e\right)^{-1} \cdot\left(e^{-1}\right)^{-1}\right) \cdot\left(b^{-1} \cdot\left(c^{-1} \cdot e\right)\right)$ for all

$a, b, c \in S$.

$=\left(\left(a^{-1} \cdot e\right)^{-1} \cdot e\right) \cdot(b *(c * e))$ for all $a, b, c \in S$.

$=\left((a * e)^{-1} \cdot e\right) \cdot(b * \quad(c * e))$. Since $e$ is

identity elemnt of $\mathrm{S}$, we get

$=(\mathrm{a} * \mathrm{e})^{-1} \cdot(\mathrm{b} *(\mathrm{c} * \mathrm{e}))$ for all $\mathrm{a}, \mathrm{b}, \mathrm{c} \in \mathrm{S}$.

$=(\mathrm{a} * \mathrm{e}) *(\mathrm{~b} *(\mathrm{c} * \mathrm{e}))$.Since $\mathrm{e}$ is identity

for $*$ on $\mathrm{S}$.

$=a *(b * c)$ for all $a, b, c \in S$.

Then * satisfying ATL law.

(ii) Satisfying from our hypothesis (e is a right identity element for $*$ on $\mathrm{S}$ ).

(iii) $\mathrm{a} * \mathrm{a}=\mathrm{a}^{-1} \cdot \mathrm{a}=\mathrm{e}$ for all $\mathrm{a} \in \mathrm{S}$. Then $(\mathrm{S}, *)$ is a flower.

\section{Proposition 6}

Let $(\mathrm{S}, *)$ be a flower such that $\mathrm{a} * \mathrm{~b}$ $=a \cdot b^{-1}$ for all $a, b \in S$, then $S$ is Lahhamian group, where $(S,$.$) is a group.$

Proof:We have $a * b=a \cdot b^{-1}$ for all $\mathrm{a}, \mathrm{b} \in \mathrm{S}$.Then we must prove $\mathrm{a} * \mathrm{~b}=\mathrm{b} * \mathrm{a}$ for all $a, b \in S$.Then we suppose $a * b \neq b * a$ for some $a, b \in S$.Then

$a \cdot b^{-1} \neq b \cdot a^{-1}$ for some $a, b \in S$. Then $a \cdot b^{-1} \cdot a \neq b \cdot a^{-1} \cdot a$ for some $a, b \in S$. Then $a \cdot b^{-1} \cdot a \neq b$.e for some $a, b \in S$. Since $e$ is $a$ right identity element of $S$, we obtain $a \cdot b^{-1} . a \neq b$ for some $a, b \in S$.Then replacing $b$ by a,we get a. $a^{-1} \cdot a \neq a$ for some $a \in S$ .Then

$a . e \neq a$ for some $a \in S$, then $a \neq a$ for some $\mathrm{a} \in \mathrm{S}$.

This lead to contradiction .

Then $(\mathrm{S}, *)$ is a commutative ,by Lemma $2,(\mathrm{~S}, *)$ is Lahhamian group.

\section{Theorem 7}

Every flower is commutative. .

Proof: Suppose $(\mathrm{S}, *)$ is a flower ,then we have $a *(b * c)=c *(b * a)$ for all $a, b, c \in S$. Then by ATL law, we obtain 
$c *(b * a)=a *(b * c)$ for all $a, b, c \in S$ .Then

$\mathrm{e} *(\mathrm{c} *(\mathrm{~b} * \mathrm{a}))=\mathrm{e} *(\mathrm{a} *(\mathrm{~b} * \mathrm{c}))$ for all $a, b, c \in S, e$ is a right identity element of S.By ATL law, we get

$(b * a) *(c * e)=(b * c) *(a * e)$ for all $a, b, c \in S$. Since e is a right identity, then

$(\mathrm{b} * \mathrm{a}) * \mathrm{c}=(\mathrm{b} * \mathrm{c}) * \mathrm{a}$ for all $\mathrm{a}, \mathrm{b}, \mathrm{c} \in \mathrm{S}$.

Then

Replacing a by $(b * c)$ and $c$ by $(b * a)$, we obtain

$(b * \quad(b * c)) *(b * a)=(b * \quad(b * a)) *$

$(b * c)$ for all $a, b, c \in S$.

By ATL law,we get

$(\mathrm{c} *(\mathrm{~b} * \mathrm{~b})) *(\mathrm{~b} * \mathrm{a})=(\mathrm{a} *(\mathrm{~b} * \mathrm{~b})) *$

$(b * c)$ for all $a, b, c \in S$. Then

$(c * e) *(b * a)=(a * e) *(b * c)$ for all $a, b, c \in S$.

Replacing a by $\mathrm{b}$,we obtain $(\mathrm{c} * \mathrm{e}) *$ $(b * b)=(b * e) *(b * c)$ for all $\mathrm{b}, \mathrm{c} \in \mathrm{S}$.According to axiom (iii), we get $(c * e) *$ e $=$ e.Since e is a right identity of $\mathrm{S}$. Then $\mathrm{c}=\mathrm{e}$ for all $\mathrm{c} \in \mathrm{S}$, then $\mathrm{c} * \mathrm{~b}=\mathrm{e} * \mathrm{~b}$ for all $c, b \in S$. By Theorem 4 , We get $b=e$ for all $b \in S$. Then

$c * b=b *$ e for all $c, b \in S$. Since $c=e$, then $\mathrm{c} * \mathrm{~b}=\mathrm{b} * \mathrm{c}$ for all $\mathrm{c}, \mathrm{b} \in \mathrm{S}$. Then $(\mathrm{S}, *)$ is commutative.

\section{Corollary 8:}

Let $(\mathrm{S}, \mathrm{o})$ be a flower with left and right translation of $\mathrm{S}$, then $(\mathrm{S}, \mathrm{o})$ is Lahhamian group.

Proof:By Lemma 3 ,left and right translation are commutative i.e. $(\mathrm{S}, \mathrm{o})$ is commutative flower ,by Lemma 2 , we get $(\mathrm{S}, \mathrm{o})$ is Lahhamian group.

\section{Theorem 9}

The Boolean ring $(\mathrm{S}, *, \diamond)$ is garden ,where $(\mathrm{S}, *)$ is Lahhamian group.

Proof: (i)By Proposition $7,(\mathrm{~S}, *)$ is flower .

(ii) For all $a, b, c \in S^{*}$,we have $\mathrm{a} \diamond(\mathrm{b} \diamond \mathrm{c})$,replacing $\mathrm{b}$ by $\mathrm{c}$, we obtain

$\mathrm{a} \diamond(\mathrm{b} \diamond \mathrm{c})=\mathrm{a} \diamond(\mathrm{c} \diamond \mathrm{c})$. Since $\mathrm{c} \diamond \mathrm{c}$ $=c, c \in S^{*}, S$ is Boolean ring, then obtain

$=\mathrm{a} \diamond \mathrm{c} \quad$,By replacing $\mathrm{c}$ by $\mathrm{a}$,we

$$
=\mathrm{a} \diamond \mathrm{a}=\mathrm{a} \text {. }
$$

Also, we have c $\diamond(b \diamond a)$,by same method, we obtain $\mathrm{c} \diamond(\mathrm{b} \diamond \mathrm{a})=\mathrm{a}$.

Thus, we obtain $\mathrm{a} \diamond(\mathrm{b} \diamond \mathrm{c})=\mathrm{c} \diamond(\mathrm{b} \diamond \mathrm{a})$ for all a,b,c $\in \mathrm{S}^{*}$.

i.e. $\diamond$ is ATL law.

\section{Theorem 10}

Let $(\mathrm{S}, *, \diamond)$ be a garden ,then

(1) $(\mathrm{a} \diamond \mathrm{b}) *(\mathrm{c} \diamond \mathrm{d})=\mathrm{o}$ for all $\mathrm{a}, \mathrm{b}, \mathrm{c}, \mathrm{d} \in \mathrm{S}^{*}$.

$(2) c^{*} \quad(b \diamond a)=0$ for all $c \in S, a, b \in S^{*}$.

(3) $0 \diamond 0=0$.

$(4)(a * b) \diamond\left(c^{*} d\right)=0$ for all $a, b, c, d \in S$.

Proof:(1) We have $(\mathrm{a} \diamond \mathrm{b}) \quad * \quad(\mathrm{c} \diamond \mathrm{d})$ ,replacing $\mathrm{a}$ by $\mathrm{c}$ and $\mathrm{b}$ by $\mathrm{d}$, we obtain $(\mathrm{a} \diamond \mathrm{b}) *(\mathrm{c} \diamond \mathrm{d})=(\mathrm{c} \diamond \mathrm{d}) *(\mathrm{c} \diamond \mathrm{d})=\mathrm{o}$ for all $\mathrm{c}, \mathrm{d} \in \mathrm{S}^{*}$. (o is a right identity element of $(\mathrm{S}, *))$.

(2) By replacing $\mathrm{c}$ by $(\mathrm{b} \diamond \mathrm{a})$, we get

$c^{*} \quad(b \diamond a)=(b \diamond a)^{*}(b \diamond a)=0$ for all $\mathrm{c} \in \mathrm{S}, \mathrm{a}, \mathrm{b} \in \mathrm{S}^{*}$. (o is a right identity of ( $\mathrm{S}$, $*)$ ).

(3)Since o is a right identity of $(\mathrm{S}, *)$, then we have

$$
\mathrm{o} \diamond \mathrm{o}=(\mathrm{a} * \mathrm{a}) \diamond(\mathrm{a} * \mathrm{a}) \text { for all } \mathrm{a} \in \mathrm{S} .
$$

Since o is a right identity of $(\mathrm{S}, *)$,then for all $\mathrm{a} \in \mathrm{S}$.

$$
=((a * a) * 0) \quad \diamond(a * a) . \quad \text { By }
$$

distributive law,we obtain

$$
=((a * a) \diamond(a * a)) *(o \diamond(a * a)) \text { for }
$$

all $\mathrm{a} \in \mathrm{S}$.

Since o is a right identity of $(\mathrm{S}, *)$, then $=((a * a) \diamond(a * a)) *((a * a) \diamond(a * a))=0$ for all $\mathrm{a} \in \mathrm{S}$.

(4)For all a ,b,c,d $\in S$ we have $(a * b)$ $\diamond(\mathrm{c} * \mathrm{~d})$. By take $\mathrm{a}=\mathrm{b}$,we obtain

$(b * b) \diamond(c * d)=0 \diamond(c * d)$. Since $o$ is $a$ right identity of $(\mathrm{S}, *)$, then

$=((\mathrm{c} * \mathrm{~d}) \quad * \quad(\mathrm{c} * \mathrm{~d})) \quad \diamond(\mathrm{c} * \mathrm{~d}) \quad$.By

distributive law, we get

$=((\mathrm{c} * \mathrm{~d}) \diamond(\mathrm{c} * \mathrm{~d})) *((\mathrm{c} * \mathrm{~d}) \diamond(\mathrm{c} * \mathrm{~d}))$

$=\mathrm{O} \quad(\mathrm{o}$ is a right identity of $(\mathrm{S}, *))$. 


\section{Theorem 11}

In a garden $(\mathrm{S}, *, \diamond)$ for all $\mathrm{a}, \mathrm{b} \in \mathrm{S}$, $\mathrm{c} \in \mathrm{S}^{*}$, then $\mathrm{c} \diamond(\mathrm{a} * \mathrm{~b})=0$.

Proof: We have $\mathrm{c} \diamond(\mathrm{a} * \mathrm{~b})$, then $(\mathrm{c} * \mathrm{o})$ $\diamond(a * b)$ for all a,b $\in S, c \in S^{*}$.By distributive law, we get

$(\mathrm{c} * \mathrm{o}) \diamond(\mathrm{a} * \mathrm{~b})=(\mathrm{c} \diamond \quad(\mathrm{a} * \mathrm{~b}) *(\mathrm{o} \diamond(\mathrm{a} * \mathrm{~b}))$ for all $a, b \in S, c \in S^{*}$.

Let $\mathrm{a}=\mathrm{b}$, we obtain

$=(\mathrm{c} \diamond(\mathrm{a} * \mathrm{a})) *(\mathrm{o} \diamond(\mathrm{a} * \mathrm{a}))$ for all $a \in S, c \in S^{*}$.

Since $(\mathrm{S}, *)$ is a flower then by axiom ( iii ) ,we get

$=(\mathrm{c} \diamond 0)^{*}(\mathrm{o} \diamond 0)$. By distributive

law, we obtain

$=(\mathrm{c} * \mathrm{o}) \diamond \mathrm{o} \quad(\mathrm{o}$ is right identity of $(\mathrm{S}$,

$*))$. By Lemmal,we get $=(\mathrm{c} *(\mathrm{o} \diamond \mathrm{y}))$

$\diamond(\mathrm{o} \diamond \mathrm{y})$ for all $\mathrm{c}, \mathrm{y} \in \mathrm{S}^{*}$. By distributive

law, we obtain $=(\mathrm{c} \diamond(\mathrm{o} \diamond \mathrm{y})) *((\mathrm{o} \diamond \mathrm{y})$ $\diamond(\mathrm{o} \diamond \mathrm{y}))$ for all $\mathrm{c}, \mathrm{y} \in \mathrm{S}^{*}$. Then

$=(\mathrm{c} \diamond(\mathrm{o} \diamond \mathrm{y}))^{*} \mathrm{o}$ for all $\mathrm{c}, \mathrm{y} \in \mathrm{S}^{*}$. Since $\mathrm{o}$ is a right identity of $(\mathrm{S}, *)$,then

$=\mathrm{c} \diamond(\mathrm{o} \diamond \mathrm{y})$ for all $\mathrm{c}, \mathrm{y} \in \mathrm{S}^{*}$. By Lemma 1 , we obtain

$=\mathrm{c} \diamond \mathrm{o}$ for all $\mathrm{c} \in \mathrm{S}^{*}$. By Theorem 10(3), we obtain

$=\mathrm{c} \diamond(\mathrm{o} \diamond \mathrm{o})$ for all $\mathrm{c} \in \mathrm{S}^{*}$. By ATL law, we get

$=\mathrm{o} \diamond(\mathrm{o} \diamond \mathrm{c})$ for all $\mathrm{c} \in \mathrm{S}^{*}$. By

Lemma1,we obtain

$=0 \diamond$ o.By Theorem 10(3), we get

$=0$

As a corollary of Theorem 11, we can write

\section{Corollary 12}

Let $(\mathrm{S}, *, \diamond)$ be a garden, then for all $\mathrm{c} \in \mathrm{S}^{*}, \mathrm{c} \diamond \mathrm{O}=\mathrm{o}$.

Proof:We have $\mathrm{c} \diamond \mathrm{o}$, for all $\mathrm{c} \in \mathrm{S}^{*}$, by Theorem 10(3),we obtain

$\mathrm{c} \diamond \mathrm{o}=\mathrm{c} \diamond(\mathrm{o} \diamond \mathrm{o})$ for all $\mathrm{c} \in \mathrm{S}^{*}$. By ATL law ,we get

$=\mathrm{o} \diamond(\mathrm{o} \diamond \mathrm{c})$ for all $\mathrm{c} \in \mathrm{S}^{*}$. By Lemma1,we obtain

$=0 \diamond 0$.Again by Theorem 10(3), we get $=\mathrm{O}$

\section{Proposition 13}

In a farm $(S, *, \diamond)$ for all $a, b, c \in S$, then $\mathrm{c} \diamond(\mathrm{a} * \mathrm{~b})=\mathrm{o}$

Proof:We can write the proof of our proposition by same method in Theorem 11.

From precedence Theorem 10, Theorem 11 and Corollary 12, we can write the following remark.

\section{Remark 14}

Let $(\mathrm{S}, *, \diamond)$ be a garden ,then

$(\mathrm{a} \diamond \mathrm{b}) *(\mathrm{c} \diamond \mathrm{d})=(\mathrm{a} * \mathrm{~b}) \quad \diamond(\mathrm{c} * \mathrm{~d})=\mathrm{c} *$ $(\mathrm{b} \diamond \mathrm{a})=\mathrm{c} \diamond(\mathrm{a} * \mathrm{~b})=\mathrm{c} \diamond \mathrm{o}=\mathrm{o} \diamond \mathrm{o}=\mathrm{o}$.

\section{Theorem 15}

If $(S, *, \diamond)$ be a ring ,then $S$ with the new operations $\diamond$ and $*$ defined as follows :

$\mathrm{a} * \mathrm{~b}=\mathrm{a} \cdot \mathrm{b}^{-1}$ for all $\mathrm{a}, \mathrm{b} \in \mathrm{S}$.

$\mathrm{a} \diamond \mathrm{b}=\mathrm{a}$ for all $\mathrm{a}, \mathrm{b} \in \mathrm{S}^{*}$.Is a garden, where $(\mathrm{S},$.$) is a belian group.$

Proof:(i) By Proposition $5,(\mathrm{~S}, *)$ is a flower .

(ii) We have $\mathrm{c} \diamond(\mathrm{b} \diamond \mathrm{a})$ according to defined of $\diamond$, then $c \diamond(b \diamond a)=c \diamond b$ for all $a, b, c \in S^{*}$.Since $(a \diamond b=a)$,then

$a, b, c \in S^{*}$.

$$
=(c \diamond a) \quad \diamond(b \diamond a) \text { for all }
$$

Replacing a by $\mathrm{c}$ and $\mathrm{c}$ by a we obtain

$$
=(a \diamond c) \quad \diamond(b \diamond c) \text { for all }
$$

$a, b, c \in S^{*}$. Since $(a \diamond c=a)$ according to defined of $\diamond$, we obtain

$$
=a \diamond(b \diamond c) \text { for all } a, b, c \in S^{*}
$$

Thus $\diamond$ is ATL law.

(iii) We have $(a * b) \diamond c=a * b$ for all $a, b \in S, c \in S^{*}$. According to defined of $\diamond$,we obtain

$=(a \diamond c) *(b \diamond c)$ for all $a, b \in S, c \in S^{*}$. Thus the distributive law hold in $\mathrm{S}$.

Then $(\mathrm{S}, *, \diamond)$ is a garden .

\section{Theorem 16}

If $(S, *, \diamond)$ be a ring, then $S$ with new operation $\diamond$ and $*$ defined as follows:

$a * b=a \cdot b^{-1}$ for all $a, b \in S$ and $a \diamond b=a$ for all $a, b \in S^{*}$. Is a farm, where $(S,$.$) is a$ belian group. 
Proof:According to Theorem 15 , we have $(\mathrm{S}, *)$ is a flower and the distributive law hold in $S$,therefore, we must prove $\left(S^{*}, \diamond\right)$ is a flower ,then

(i) Form Theorem $15, \diamond$ is ATL law of $S^{*}$.

(ii) According to $\mathrm{a} \diamond \mathrm{b}=\mathrm{a}$ for all $a, b \in S^{*}$,there exists an element $e$ in $S^{*}$ such that $a \diamond e=a$ for all $a \in S^{*}$, i.e. e is a right identity element of $S^{*}$.

(iii) According to $\mathrm{a} \diamond \mathrm{b}=\mathrm{a}$ for all $a, b \in S^{*}$,then $\quad a \diamond a=a \quad$ for all $a \in S^{*}$,therefore,

$\mathrm{a} \diamond \mathrm{a}=\mathrm{a} \diamond(\mathrm{a} \diamond \mathrm{e})$. By ATL law, we get

$=\mathrm{e} \diamond(\mathrm{a} \diamond \mathrm{a})$ for all $\mathrm{a} \in \mathrm{S}^{*}$. According to defined $\diamond$,we obtain

$=\mathrm{e} \diamond \mathrm{a}$ for all $\mathrm{a} \in \mathrm{S}^{*}$.According to defined of $\diamond$,we obtain

$=$ e. Then $\left(S^{*}, \diamond\right)$ is a flower

Thus , we obtain $(\mathrm{S}, *, \diamond)$ is a farm.

As a corollary of Theorem 8 and Proposition 8 ,we write the following theorem.

\section{Theorem 17}

If $(\mathrm{S}, *)$ is a flower . Then

(i) $\mathrm{S}$ is a Lahhamian group.

(ii) $\mathrm{S}$ is has an identity.

(iii) $\mathrm{S}$ is commutative.

(iv)S is a ssociative.

The following conjecture appeared in [1] with out proof, we give the proof .

\section{Al-Lahham Conjecture 18}

If $(\mathrm{S}, *)$ is a groupoid with a right identity element $\mathrm{e}$, such that $\mathrm{x} * \mathrm{x}=\mathrm{e}$ for all $\mathrm{x} \in \mathrm{S}$, then for all elements $\mathrm{a}, \mathrm{b}, \mathrm{c} \in \mathrm{S}$ :

$\mathrm{a} *(\mathrm{~b} * \mathrm{c})=\mathrm{c} *(\mathrm{~b} * \mathrm{a})$ if and only if $(\mathrm{a} * \mathrm{~b}) * \mathrm{c}=(\mathrm{a} * \mathrm{c}) * \mathrm{~b}$.

Proof:For all a,b,c $\in \mathrm{S}$, we have a* $(b * c)=c *(b * a)$.Then we will deal with $(\mathrm{S}, *)$ as a flower. By Proposition 6 ,we get

$(\mathrm{a} * \mathrm{c}) * \mathrm{c}=(\mathrm{a} * \mathrm{c}) * \mathrm{~b}$.

Also, we have for all a,b,c $\in$ S,such that $(\mathrm{a} * \mathrm{~b}) * \mathrm{c}=(\mathrm{a} * \mathrm{c}) * \mathrm{~b}$.

Since $\mathrm{x} * \mathrm{x}=\mathrm{e}$ for all $\mathrm{x} \in \mathrm{S}$.

Then (S, *)is Lahhamian group ,by Proposition $7,(\mathrm{~S}, *)$ is flower, then a* $(b * c)=c *(b * a)$ is satisfy.

\section{References:}

1- Al-Lahham ,Anwar T.2004 ,New algebraic systems flower, garden and farm ,Damascus University Journal for Basic Sciences ,Vol.20 ,No.1 :9-19.

2- Clifford, A.H. and Preston ,G.B.1964 ,The algebraic theory of semigroups ,AMS, Vol.1.

3- Dummit ,D.S.and Foote ,R.M.1999 ,Abstract algebra ,Prentice-Hall.

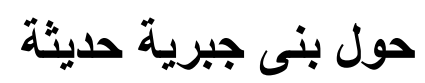
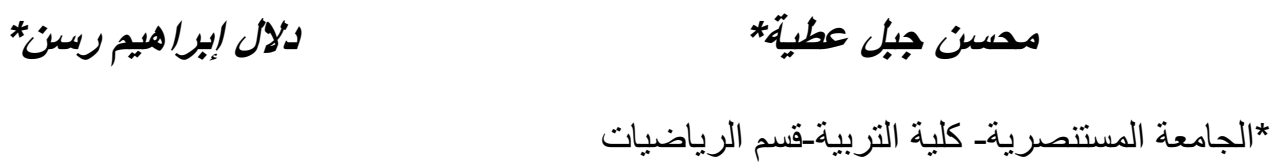

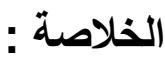

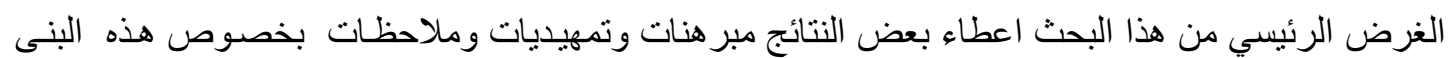
الجبرية الحديثة , الزهرة و الحديقة و المزر عة مع بنى جبرية مألوفة ,نصف الزمرة ولثيات والزمرة و الحلقة. 